\title{
Anabases
}

ANABASES Traditions et réceptions de l'Antiquité

19 | 2014

Varia

\section{Dan Dana, Métamorphoses de Mircea Éliade. À partir du motif de Zalmoxis}

\section{Yann Berthelet}

\section{OpenEdition}

\section{Journals}

Édition électronique

URL : http://journals.openedition.org/anabases/4722

DOI : 10.4000/anabases.4722

ISSN : 2256-9421

\section{Éditeur}

E.R.A.S.M.E.

\section{Édition imprimée}

Date de publication : 1 avril 2014

Pagination : 337-339

ISSN : 1774-4296

\section{Référence électronique}

Yann Berthelet, «Dan dana, Métamorphoses de Mircea Éliade. À partir du motif de Zalmoxis », Anabases

[En ligne], 19 | 2014, mis en ligne le 01 avril 2014, consulté le 22 septembre 2020. URL : http://

journals.openedition.org/anabases/4722 ; DOI : https://doi.org/10.4000/anabases.4722

Ce document a été généré automatiquement le 22 septembre 2020.

(c) Anabases 


\title{
Dan DANA, Métamorphoses de Mircea Éliade. À partir du motif de Zalmoxis
}

\author{
Yann Berthelet
}

\section{RÉFÉRENCE}

Dan DANA, Métamorphoses de Mircea Éliade. À partir du motif de Zalmoxis, Paris, Vrin-EHESS,

coll. «Contextes », 2012, $292 \mathrm{p}$.

30 euros / ISBN Vrin 978-2-7116-2421-8, ISBN EHESS 978-2-7132-2357-0

Le dernier livre de Dan Dana touche aussi bien à l'Histoire des religions qu'à l'Histoire de l'Antiquité et à celle de l'Europe orientale contemporaine. Selon les termes de l'auteur, il ne s'agit « ni d'une nouvelle biographie d'Éliade, ni d'une analyse de ses théories, mais d'une radiographie d'un segment de son œuvre, en rapport avec la réalité de sa vie ». Le segment de l'œuvre mentionné est le motif de Zalmoxis, un dieu des Gètes. Après avoir publié une thèse sur les controverses autour de ce dieu (Zalmoxis de la Herodot la Mircea Eliade. Istorii despre un zeu al pretextului, Iaşi, 2008) et un recueil des sources relatives, avec traductions et commentaires (Fontes ad Zalmoxin pertinentes. Accedunt fontes alii historiam religionum Thracum Getarum Dacorumque spectantes, Iaşi, 2011), Dan Dana reprend le motif de Zalmoxis : cette fois, l'enjeu est de mettre au jour l'idéologie d'Éliade et son rapport problématique à la discipline historique, par une mise en contexte de ses productions sur l'histoire et la spiritualité roumaines, et leur confrontation aux témoignages de sa correspondance et de son Journal portugais. L'ouvrage, préfacé par François Hartog, se divise en sept chapitres. Le premier d'entre eux souligne l'influence de plusieurs intellectuels roumains des années 1920-1930 sur le jeune Éliade : le professeur Nae Ionescu, qui l'entraîna sur la voie du nationalisme et de l'« orthodoxisme »; l'archéologue Vasile Pârvan, à l'origine d'une conception idéaliste, spiritualiste et mono/hénothéiste de la religion gète ; le poète et philosophe Lucian Blaga, promoteur d'une révolte du fonds rural et non-latin des Roumains. C'est dans ce contexte que le jeune Éliade décida de promouvoir le folklore, l'ethnographie et la préhistoire roumaines dans la revue Zalmoxis (1938-1942), 
à laquelle collabora Ioan G. Coman, théoricien d'un (pré)monothéisme gète précurseur du christianisme, et que de nombreux intellectuels roumains, dont Éliade et Cioran, adhérèrent au mouvement d'extrême-droite, nationaliste et ultra-orthodoxe de la Garde de Fer. Les seules sources sur Zalmoxis étant grecques et littéraires, l'unique histoire possible est celle de leurs interprétations. C'est pourquoi l'auteur revient, dans le deuxième chapitre, sur l'apparition littéraire de Zalmoxis chez Hérodote 4.94-96: d'après un premier témoignage, véridique selon l'auteur grec, les Gètes avaient coutume, tous les quatre ans, de rendre immortel (athanatizein) l'un d'entre eux en le sacrifiant pour qu'il leur servît de messager auprès de Salmoxis ; selon un autre témoignage, plus douteux, Salmoxis aurait été un ancien esclave de Pythagore qui trompa les Thraces en leur faisant croire à sa mort puis à sa réapparition. Dan Dana montre que nombre d'Anciens et de Modernes se sont laissé abuser par le terme athanatizein qui, loin de renvoyer à une croyance générale des Gètes en l'immortalité, fait référence au rite périodique du sacrifice humain par lequel ce peuple transmettait ses requêtes au dieu : le passage d'Hérodote nous en apprend moins sur les croyances gètes que sur l'imaginaire grec du ve s. av. J.-C., où il était inconcevable qu'un sacrifice humain fit accéder à l'immortalité, et sur l'imaginaire chrétien des Modernes, marqué par les concepts de « croyance » et d'« immortalité ». L'essai publié par Éliade en 1970, De Zalmoxis à Gengis Khan, qui établit durablement la figure d'un dieu de l'initiation et des Mystères, n'échappe pas à ces présupposés nationalistes et spiritualistes sur un Zalmoxis censé avoir préparé la voie au christianisme, sans parler de l'influence gardiste des noces avec la mort et du sacrifice créateur. Dans les deux chapitres suivants, Dan Dana souligne combien les métamorphoses et les camouflages qu'Éliade prête à Zalmoxis s'appliquent d'abord à sa propre personne : c'est en se considérant luimême comme " un cheval de Troie dans le camp scientifique » qu'il décida, pendant la Seconde Guerre mondiale, d'entamer une carrière en Occident pour dépasser le provincialisme du « roumanisme » et transmettre au monde son appel à un renouveau spirituel. C'est de même à son propre exil que s'applique le mieux la dimension initiatique qu'il attribue au dieu gète : épreuve initiatique de l'exil qui l'amena à donner une réponse religieuse à la " terreur de l'Histoire ", attribuant à la Roumanie une mission historique de sacrifice. Le sixième chapitre analyse la double récupération de l'œuvre d'Éliade dans la Roumanie nationaliste de Ceausescu : par le régime en quête de légitimité et par l'intelligentsia en recherche d'une alternative au discours officiel. Le dernier chapitre est consacré à la réception actuelle de l'œuvre d'Éliade en Roumanie, où l'on continue à défendre la non-contamination de l'œuvre « scientifique » par l'idéologie de son auteur. Les qualités de l'ouvrage de Dan Dana sont évidentes : érudition, finesse de l'analyse et sûreté de la méthode. On regrettera néanmoins, alors qu'il existe d'inutiles répétitions et des citations-doublets, que le passage d'Hérodote 4.94-96 n'ait pas été cité. On gagnera aussi à élargir la réflexion menée à partir du cas d'Éliade, afin d'en mieux saisir l'actualité : aujourd'hui encore, une certaine historiographie allemande et anglo-saxonne nie l'Histoire des religions en tant que méthode scientifique au profit d'une sorte de philosophie ou de théologie christianisante - dénoncée récemment par John Scheid dans Les dieux, l'État et l'individu. Réflexions sur la religion civique à Rome, Paris, 2013. C'est tout le paradoxe de l'héritage d'Éliade : avoir largement contribué, depuis Paris et Chicago, à institutionnaliser l'Histoire des religions, sans avoir su la fonder méthodologiquement. 


\section{AUTEURS}

YANN BERTHELET

Fondation Thiers-CNRS

yann.berthelet@normalesup.org 